\title{
The Expansion of Production, Marketing and Consumption of Chat in Ethiopia
}

Tesfa Binalfew

Melkassa Agricultural Research Center

\begin{abstract}
Chat (Catha edulis) is a plant of uncertain and very debatable status grown in Ethiopia. The chewing of chat leaves has a deep-rooted religious and socio-cultural tradition. It is considered a cash crop and source of economic value to the societies and nations involved. However, there have been reports of negative economic effects on the individuals engaging in the habit of chat chewing. The paper discusses the increasing importance of chat as a major cash crop in the Ethiopian and the controversies that its production and marketing generates. It also presents and discusses the results of the CSA and Revenue data through summarizing. The results of the review show the opportunities and challenges related to chat production and export to Ethiopia's neighboring countries in the process of internationalization. The strategic and policy implications of the results are also addressed. Chat export earnings about $10 \%$ share with annual growth of $17.4 \%$.
\end{abstract}

Keywords: Chat, economy, dilemma, constraints.

\section{INTRODUCTION}

Chat belonging to family Celastraceous is considered an evergreen plant, cultivated for the production of leaves having sympathomimetic actions which are used commonly for gradual chewing. This plant is called by different names in different countries: 'chat' in Ethiopia, 'qat' in Yemen, 'mirra' in Kenya and 'qaad' or 'jaad' in Somalia. In Ethiopia, this is grown extensively in the middle altitudes between 1500 and 2100 meters above sea level (masl), and performs better on well-drained soil under diverse climatic conditions. It can tolerate drought conditions for several months. The crop can be harvested throughout the year, thereby becoming a source of continuous income for the producers. The economically important parts of the plant are its young leaves and tender twigs, which are chewed for their stimulating effect. Chat production and consumption occupy a major area in eastern Africa, South-west Arabia, and Madagascar (Pantelis et al. 1989).

Ethiopia is the world's largest producer of chat which has become the fastest growing export commodity. The history of domestication and introduction of this crop in Ethiopia is not known. According to the folklore, it was first introduced in Harar from where it spread to rest of the country (Getahun and Krikorian 1973). About a third of the production is exported to neighboring countries like Djibouti and Somalia. However, it is largely produced, marketed and consumed within the country. The bulk of the chat produced in Hararghe is of good quality and is in great demand in both domestic as well as in export markets. In 1998-99, the crop accounted for 13.4\% of Ethiopia's export earnings and was the country's second largest export items that year (CSA 2000). Consumption of chat leaves is common in Middle-East Asian countries like Yemen, Saudi Arabia and East African countries like, Kenya, Somalia, Djibouti, Uganda and Tanzania.

With globalization of chat consumption, the stimulant has found new markets, both within the region of production and internationally. In response to increased demand, more and more farmers in Ethiopia are giving up other crops and concentrate upon chat. Chat is one of the major sources of export earnings of Ethiopia. It is exported to various parts of the world including Djibouti, UK (London), Somalia, and a number of Arab countries. Since the formal export to Aden in 1942 markets were developed (when exports totaling 1,485.8 metric tons valued over Birr 6.4 million were recorded), exports have increased dramatically. In 1999/2000 Birr 0.464 billion worth of chat was exported to different countries and ranked second replacing hides and skins in export revenue (The Reporter, 2000). The above figure, does not, however include the huge volume of chat smuggled to different countries. 
The government has a policy of non-engagement with questions of chat production, marketing and consumption (Feyisa and Aune, 2003). Where economies have been devastated by the collapse in livestock and coffee markets, this perhaps is understandable. However, the questions associated with chat extend beyond the borders of Ethiopia into the globalized economy. Chat is being produced and traded not only within the Horn of Africa but is also exported to Europe and North America including to the US, where chat has been classified as an illicit narcotic. From neighboring Somalia to distant Afghanistan and Colombia, the global community has become increasingly concerned about how humanitarian crises and conflict can lead to sharp increases in narcotic activities, with related security implications for local and international community's (Lautze et.al, 2003).

Though officially discouraged, chat stands among the most important cash crops in Ethiopia, with strong markets domestically as well as in neighboring Somalia, Djibouti, Yemen and the Gulf State. As a cash crop commonly grown in food insecure parts of the country, the need to understand better the cultivation, botanical characteristics and economics of the plant is very important. On the other side it is better to understand the negative side of the plant and precede its production in such a way that compatible with other horticultural crops.

Therefore, the objective of this paper is to appraisal the current production status of chat in comparison with other horticultural crops in Ethiopia.

\section{WHAT IS CHAT?}

Much of the lore of chat has been passed on orally from generation to generation, leaving inadequate written records largely due to lack of interest in the crop by institutions, policy makers and researchers. Hence, the history of its importance as a crop is neither clear nor certain.

Some oral traditions claim that chat originated from Yemen, however the literature indicates that chat originated from Ethiopia, specifically in Hararghe with a gradual expansion to different parts of Ethiopia, Yemen and other parts of the world (Dechassa, 2001).

\section{The Chat Plant}

Chat is an evergreen perennial shrub plant. The plant is known with different vernacular names: Khat in English and in Arabic, Jimaa in Oromo and chat in Amharic languages. Chat usually grows up to 7 meters but occasionally reaches as high as 15 to 25 meters. Leaves are simple, elliptic, and oblong and are glossy green above but lighter below, leathery and stiff tapering to both ends. The buds and leaves contain an alkaloid and are chewed in a fresh or dried condition as a stimulant. Flowers are small and white. The fruit is smooth and narrow splitting to release narrowly winged reddish seeds when matured. The stem is straight and slender; the bark has different colors depending on the variety and age of the stem and branches. The young branches are smooth and green to pinkish but grey and sometimes rougher and darker on older branches and stems. The root system can grow as deep and as long as 3-5m (Raman, 1983).

\section{Uses}

In Ethiopia chat is an important and potentially lucrative cash crop. The employment opportunity created through the cultivation of chat is very high in that large numbers of people are involved in growing, harvesting, sorting, packing, transporting, loading and unloading the commodity. Chat is profitable to the huge number of people involved in its production and marketing, including farmers, distributors and merchants. The taxes imposed on chat are also an important source of revenue to governments.

The wood of the plant is commonly used for fuel and due to its resistance to termite is used in the construction of houses and fencing. It is also used for making rafters, handles of farm tools (hammers and chisels) and handles of household articles such as pots and pans, rolling pins, and to make forks, combs, spoons and for rulers.

Students and a number of staff in higher education institutions and high schools are using chat to "increase" their concentration levels and attention span.

Some of the farmers' responses that chat give them energy and strength to accomplish a great deal of agricultural and other hard work, which they say, would otherwise be impossible. This is common in Hararghe where hand cultivation is extensively used in seedbed preparation and cultivation; chat 
chewing enables them to accomplish the work without fatigue. They also cited the additional "advantage" of a reduced appetite in food shortage periods. The crop also has prestige value for people who grow large quantities (Tesfaye, 2003).

Chat has considerable social value. It is served to welcome and entertain guests, in mourning, weddings and circumcision ceremonies and collective labour works. Chat chewing has its own associated ceremonies like smoking of incense, cigarettes and use of drinks (soft drinks, tea and milk).

Chat chewing has a deep-rooted religious and socio-cultural tradition. It is especially highly regarded as a social event, where it is used for recreation and relaxation. For the participants in chat sessions, it is also a way of redefining their identity and reinforcing self-esteem both at home and as migrants in an alien society. At the same time, chat sessions are an important source of news from home and an opportunity to exchange information on the society in which those involved in chat chewing find themselves.

Chat cultivation plays key role in scheming soil erosion, which is a major threat in the Ethiopia due to the undulated topography and intensive deforestation for farmland expansion and hence chat culture is considered the best agro-forestry system practiced by farmers. For example, had it not been for the cultivation of chat, the erosion of topsoil would have been severe and possibly disastrous in midland areas of East and West Hararghe zones.

\section{Demerit of Chat}

Chat chewing is addictive and has negative physical, economic and social connotations. Although non-users both in rural and urban areas condemn the practice of chewing, the number of people chewing is increasing particularly among the youth. In urban areas, chewing chat is a common leisure activity which, combined with the consumption of it, followed by alcohol is having an adverse effect on family life.

Farmers in eastern Ethiopia often start chewing chat right after breakfast and work for about 3 hours without any feeling of fatigue. After lunch, they resume chewing and work through the remaining afternoon with intermittent chewing. It is evident that chat chewing competes for active working time in that the actual working hours do not exceed 6-8 hours a day. Furthermore, in areas where chat chewing is common, such as in Afar, Somali regions and Hararghe zones of Oromia region, punctuality of business appointments is a frequent problem, as the time after lunch is usually spent in chewing chat.

\section{DISTRIBUTION OF CHAT IN ETHIOPIA}

The distribution of chat in tropical Africa extends from north Arabia to South Africa. In Africa it is well established in Ethiopia, Eritrea, Somalia, Kenya, Tanzania, Uganda, Burundi, Rwanda, Democratic Republic of Congo, Zambia, Zimbabwe and South Africa, despite efforts of the respective governments to discourage its cultivation. In East Africa it grows in the range of 1500-2500 meters above sea level (masl). Outside Africa it is planted in the Arabian Peninsula, Yemen, Afghanistan, India and Sri Lanka for consumption and in the USA, UK and France for experimental purposes (Dechassa, 2001).

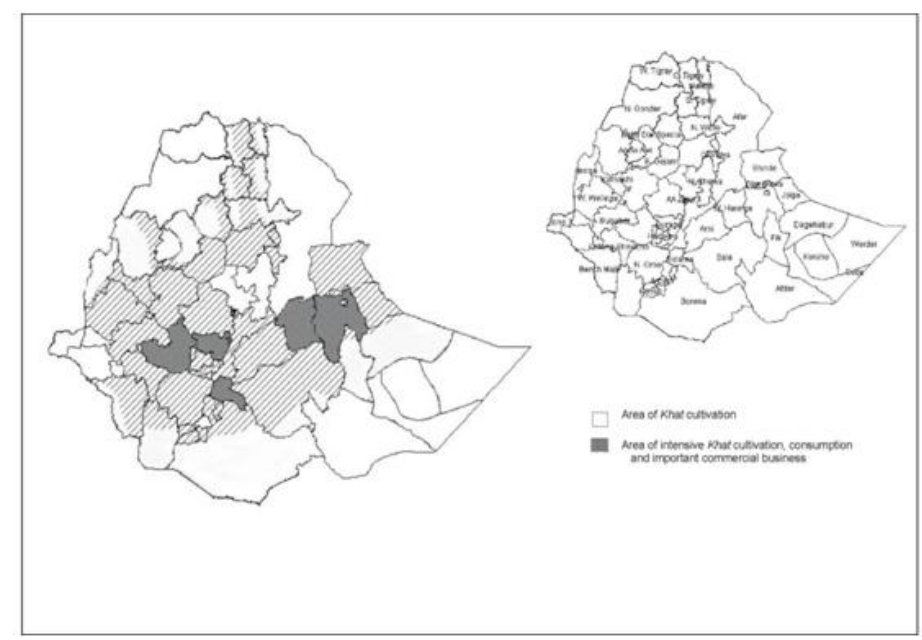

Figure1. Map showing distribution (rough) of chat in Ethiopia (adopted from Dechassa 2001)

The major production area of chat in Ethiopia is the Hararghe highlands located in eastern Ethiopia. It has however been observed chat production has also been expanding in other regions of the country. 
Tesfa Binalfew "The Expansion of Production, Marketing and Consumption of Chat in Ethiopia"

Farmers have developed appropriate spacing, defoliation time, other cultural practices, cultivar selection and disease control methods including use of chemicals such as DDT. All of these were popularized and done independently without any government involvement or assistance from farmers' associations.

Despite silent support and objection against the crop by development institutions, chat is cultivated and expanding in different parts of Ethiopia. At present chat is being grown for sale not only in its traditional areas in Hararghe but in Jimma, Shashemene, Sidama, Kembata, Gurage, and even as far as Debre Libanos, Gojam, Wollo and Tigray.

The expansion of chat plant in Ethiopia has been increasing radically. If we investigated the total area of chat plant some thirty years back was 3000ha, 3500ha and 6997ha in 1954, 1957 and 1961 respectively (Amare and Krikorian ,1973). According to CSA the total area of land under chat cultivation in the year 1998 was estimated at 78,570 ha in 2008 increased to 163,227 ha and then 204,648 ha in 2011 and in 2015 it reached 248,964 ha. Correspondingly the yield gained has increased. However, there is little improvement in productivity of the crop through time (fig 1).

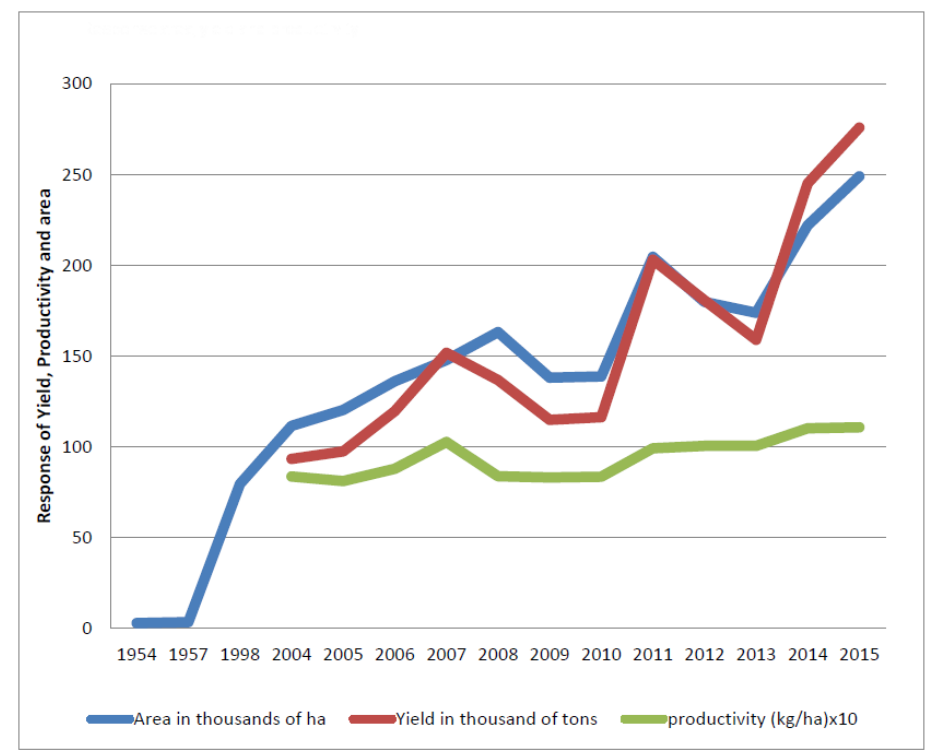

Figure2. Chat Production Trend in Ethiopia: 1954-2015

Source: Calculated form CSA data, Amare and Krikorian, 1973

Oromia, mainly East and West Hararghe zones, is the most important centre of chat production. The two zones alone contribute half of the total product in Ethiopia. Hararghe is also considered as the most important producer of quality chat in the world.

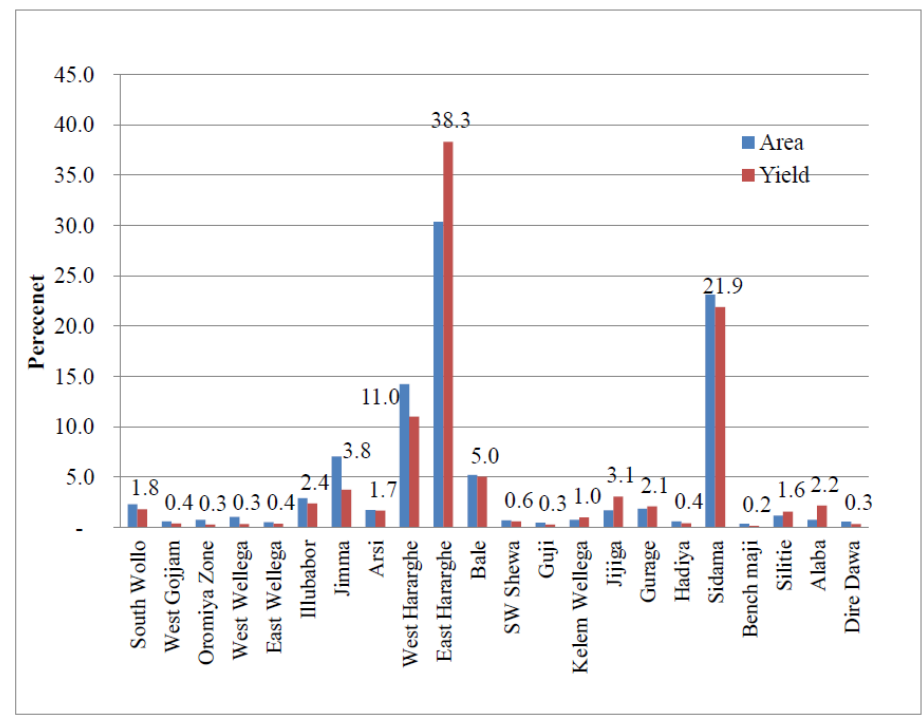

Fig3. Share of Major Chat Producing Zones in Ethiopia, CSA-2015

Source: Calculated form CSA 2015 


\section{Chat Expansion and Policy Issues}

The increasing use and consumption of chat has become a major concern to many countries especially to Djibouti, Somalia and Ethiopia who have found it necessary to prohibit its cultivation at different times. Nevertheless, past efforts to ban the crop in these countries and to replace it with other crops in Ethiopia and uprooting the crop after paying compensation in Somalia did not last long. The failure was largely due to the exclusion of the farmers from the decision-making process and more importantly, due to an absence of any viable substitute that could fully compensate the merits (traditional, economic, social, environmental benefits) obtained from the cultivation of chat. Chat sparked a commission of inquiry, under the supports of the League of Nations and the UN Commission on Narcotics and Drugs (UNCND) found the issue of chat consumption and its effects quite controversial often postponing several meetings as the plant's narcotic effect was insufficiently understood due to lack of viable clinical research information (Dechassa, 2001).

The legality of chat, however, varies from country to country. The economic effect of chat on individuals and societies that engage in chat chewing furthermore seems uncertain; these uncertainties make the habit of chat chewing controversial and ambiguous. The increasing use of chat and the negative attention have led to the present uncertain status of this once indigenous practice.

Lautze et. al. (2003) argued that the expansion of chat cultivation to extraordinary levels poses a dilemma for food security. Some suggest that the cultivation of chat will grow unabated at the expense of other crops in the coming years, thereby reducing both household and national production of staple foods. Staple crop losses due to increasing chat production will look on the national balance sheet as though there has been a straightforward loss in food security due to an apparent decline in food availability rather than taking into consideration positive income effects associated with chat production.

Tefera et.,al (2003) explained that the most important lesson that policy makers can learn from the chat case is that the provision of research and extension service is on its own insufficient to get smallholder agriculture 'moving'. Delivering research and extension service will only bring the urgently needed quantum leap in the increase in production and productivity to feed mouths growing at unprecedented rate in Ethiopia and elsewhere in the Sub-Saharan Africa if and only if it is combined with creation of market incentives.

Without an international agreement on chat, akin to the 1961 Single Convention on Narcotic Drugs which specifically prohibits the production, distribution and possession of a list of substances cannabis, coca and cocaine, opium and derivatives - the status of chat is determined by national legislation. With a number of core countries engaged in large scale production, and emerging markets in the Diaspora, the export trade is bound to continue for some years to come. More dramatic still is the expansion of chat production into new areas along the shifting chat frontier (Klein, 2008).

Expansion of chat production in the Ethiopia has mainly been driven by market incentives. According to Tesfaye et. al. (2003) shifting the scarce land and other resources to chat has significantly increased rural income, positively contributed to food and nutrition security of the households, and soil conservation. It has also become an additional source of the foreign exchange earnings for the country. A major shift to chat production and using proceeds from chat sales to finance the adoption of improved technology and fill grain deficit has prevented or postponed the total collapse of livelihoods in this part of the world.

The policy dilemma for the government is vested in two alternative policy scenarios. One option is to accept chat production as a major contributor to livelihoods of the households and to use part of the tax revenue it generates to support the enterprise. The second option is to continue considering chat as a 'drug' and perhaps enforce a shift to other cash crops as the previous government attempted in vain. The first option is considering legal chat production but in such a way that with integrating other field crops. Few non-farm job opportunities will exist in the absence of the chat sector since chat processing, packaging, transporting and distributing is currently the single most important source of alternative employment and income. The policy makers should also be reminded that serious negative health effects of smoking are scientifically well established yet the production and marketing of cigarettes has continued to protect income and employment. Indeed, health impact of chat is not yet well established and likely to be tolerable. However, discarding nutritionally and economically important vegetables, fruits and coffee and replacing with chat has immediate and long-term effects on the society. 
So far governments in Yemen, Ethiopia, and Kenya have resisted calls for tight controls, even though the issue of chat remains contested. All these countries experienced some form of control during the colonial era, French Djibouti (1956-57), British Somaliland (1921-57), South Yemen (1957-58) and Kenya $(1945$ - 1956), and many policy makers are aware of health problems and the drop in productivity. Yet, the substance is so culturally embedded and the economic benefits so important that the idea of a ban is unthinkable. For Ethiopia, chat remains a key export.

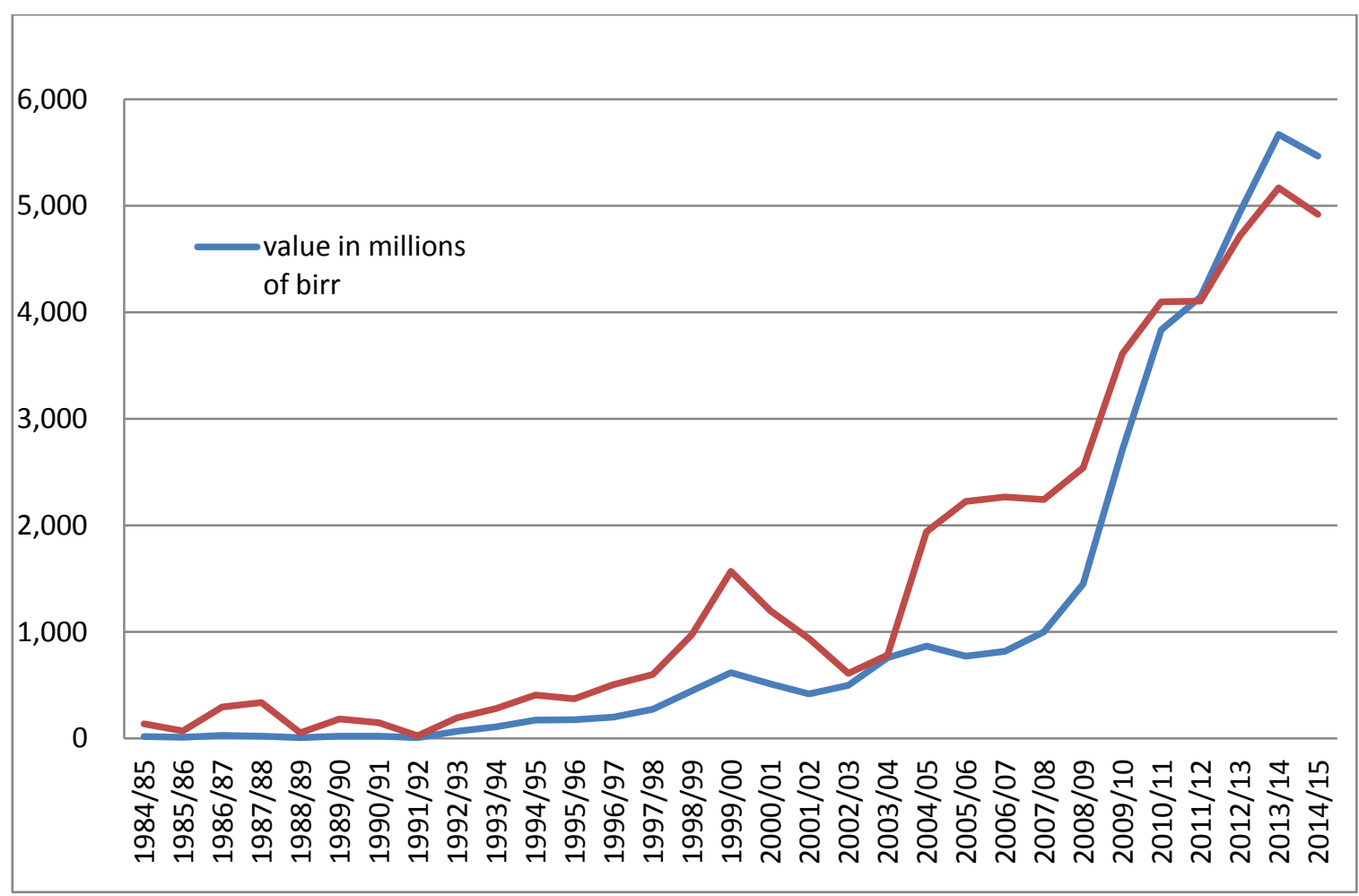

Figure5. Value and volume of chat exported of Ethiopia over years

Source: ECRA, 2016: Klein, 2008

In the meantime, chat production is moving swiftly into new parts of Africa, providing consumers with a low cost form of entertainment in rapidly urbanizing continent and farmers with a new cash crop. In each country where chat use takes root discussion over the legality take place. Where governments follow the advice of international agencies to control the substance, like in Rwanda or Tanzania a lively contraband trade develops. Countries with ambivalent control regimes, like Uganda, engage in long public discussion while production increases and consumption picks up ( Klein 2008).

\section{Factors Contributing for the Expansion of Chat}

There are a number of factors that are contributing to the expansion of chat production in the Ethiopia. The first, perhaps the most important, is growing domestic and export markets for chat and improved access to these markets an improved transport network. The export market is substantial and expanding. This includes countries such as Djibouti, Somalia and some Arab countries such as Yemen. Chat is also exported to Europe, but is banned in Canada and the United States of America. The Hararghe highlands' location and its superior transport network have played an important role in the expansion of chat since the product has to reach its final destination fresh and therefore fast transport is needed. In the domestic market, it is quite evident that chat chewing has become a recreation activity and now also forms part of the culture of the urban youth (Tesfaye et. al., 2003).

Farmers in a number of areas in Ethiopia grow chat, which is used as a stimulant, and which provides considerably greater incomes than can't be achieved with the cultivation of other cash crops, including coffee. Less labour and fewer other inputs are required for the cultivation of chat than for other cash crops.

Chat has not only been of significant benefit to the Ethiopian economy, it constitutes in terms of both bulk and value one of the most important items of trade between Ethiopia and neighboring countries Somali and Djibouti. This is particularly significant in the light of the continuing lack of horizontal linkages between African economies (Klein, 2008). 
Tesfa Binalfew "The Expansion of Production, Marketing and Consumption of Chat in Ethiopia"

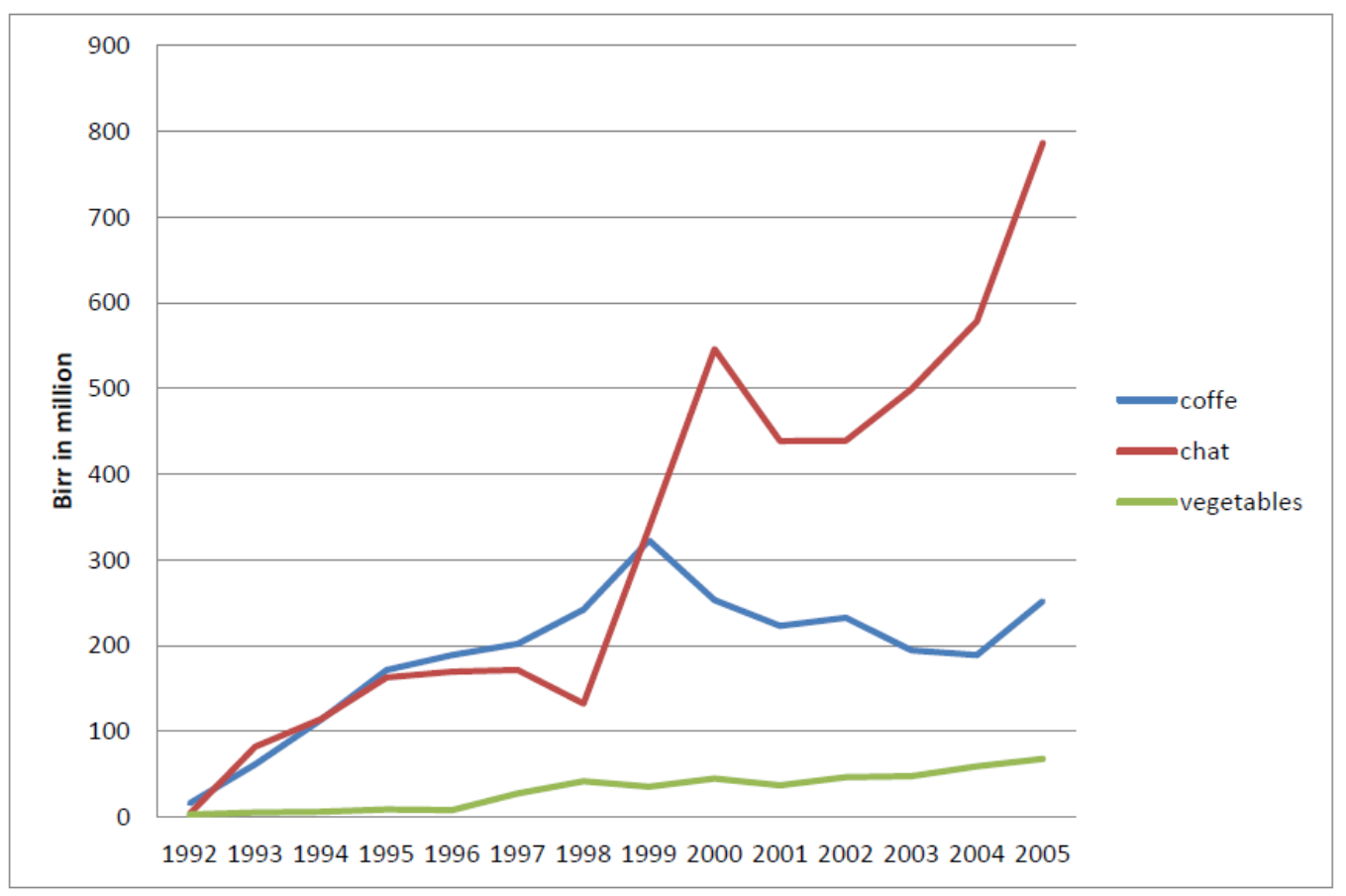

Figure6. Export Earnings from Eastern Ethiopia, 1992-2005 (in Million Birr).

The export price is also rising. While chat enjoys a relatively stable price at the world market, coffee suffers from both fluctuating export volumes and prices. As it is observed in the figure above the export earning of chat is still rising while the value from coffee drop down the earning from fruits and vegetables is remain minimal through time. Producing chat has thus become a viable and important alternative to ensure continued cash income. Chat has additional advantage because it can be harvested at least twice a year under rain fed agriculture while up to five harvests per year is possible under irrigation. This ensures that households have a well distributed flow of income.

Another economic factor for the growing interest in chat production is related to its cost of production relative to other competing enterprises. Labour is the most important cost item in the production of chat. Rapid population growth in the highlands of Ethiopia has provided enough family labour or highly cheap hired labour for labour-intensive production, making chat production feasible. In the second place, chat is hardly affected by any disease except some damage by insects that can easily be controlled by locally developed methods at little or no cost. Chat need for minimum off-farm inputs makes its production compatible with poor farmers' limited access to credit (Tefera et.al, 2003).

\section{Chat and Horticultural Crops}

Enriched with diversified agro ecologies, Ethiopia is a country where different types of horticultural crops including fruits, vegetables and herbs are successfully produced under small-scale farming. Production of horticultural crops in Ethiopia has long been meant for home consumption and local markets. With the availability of tropical and sub-tropical climatic conditions in Ethiopia, peoples intended to involve in this sector could produce variety of fruits, vegetables and herbs that the current world is demanding. So long as growers demonstrated safety of products and consistent enough in the supply of produces in the desired amount and time, they could successfully satisfy local demand and penetrate in to the international markets (Hailab et al., 2011). However, the ever increasing chat demand and market incentives, forced most Ethiopian farmers to allocate their scarce land resource from fruit and vegetable production to mono-cropping pattern of chat production, such as eastern Hararghe.

In some areas of the Hararghe highlands, in particular the chat-belt of Haramaya, it was found that the area of cropland allocated to chat is as high as $75 \%$ of total arable land (Save the Children Fund/UK, 1996). According to the survey (Tefera) area, cropland area allocated to chat ranges from $21 \%$ in Kuni (Chiro District) to $54 \%$ in Haramaya. It was also observed that the majority of irrigated land is allocated to chat production and in addition, chat enterprise consumes most of the scarce organic manure in farm households. It can be grown rain fed and/or irrigated, though the later covers less than $20 \%$ of the total chat production area. The crop could be planted both in home garden and in the field. 
The expanding geographic and social distribution of the production and consumption of chat has specific implications for food security. Originally used as a social pastime among predominantly Muslim populations, more women and children are now consuming chat, while its use is now widespread among many Christian and Muslim and rural and urban populations alike (Lautze et. al, 2003).

Guinand (1999.) indicated that chat and coffee are the two major cash crops produced in Hararghe. Whereas chat witnessed a tremendous boom these days, coffee is facing a major drawback due to unstable and decreasing prices at the international stock exchanges. Many farmers opted and are opting to cut down their coffee plantations and to replace them with chat bushes. But chat is not only taking coffee's place, it is also planted in favour of staple crops. Many parts of the Hararghe highlands, East and West Hararghe alike, are beginning to turn into a monoculture landscape with chat being the dominant crop planted and seen everywhere.

According to Feyisa and Aune 2003 study results in Habro District, Western Hararghe as Quoted Chat production in this district is rapidly replacing cereal and coffee production. About $70 \%$ of farmers' income in the study area is currently obtained from chat. One important reason for the expansion of chat production is that the chat-maize intercropping system is 2.7 times more profitable per hectare than maize mono-cropping. Chat is also less risky to grow than cereals and coffee because it is less vulnerable to drought. Increased production leads to changes in livestock composition because oxen are far less needed for ploughing in the chat-based system; moreover, availability of crop residues for fodder is reduced when chat expands. Chat growing farmers, therefore, give more emphasis to milk-producing animals such as cows and goats. It was found that chat producers also are consumers of chat and that chat consumption has become widespread in the nearby secondary school. Chat consumption negatively affects peoples' working capacity. Hence, unskilled chat consumers in urban areas are paid 7 birr (US\$ 0. 84) per day, whereas non-chat users are paid 10 birr (US\$1.22).

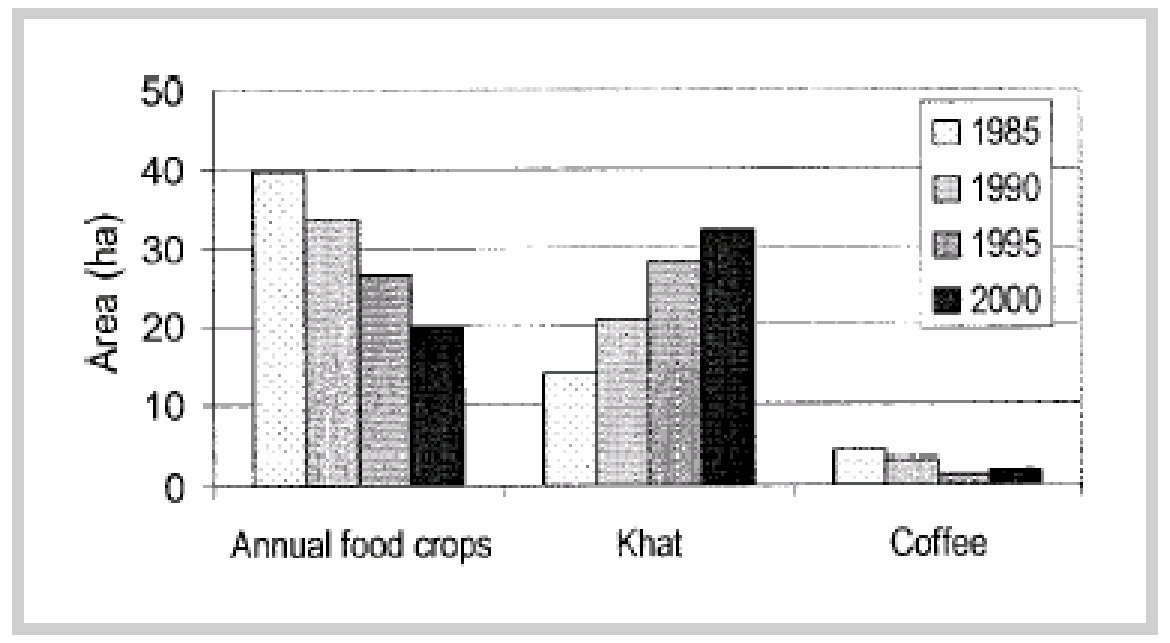

Figure7. Chat Production Supplanting Food Crops and Coffee, Results of a Survey, Habro District, Hararghe

Source: (Feyisa and Aune, 2003)

\section{Small-Scale Irrigation}

Small-scale irrigation can promote rural food security, poverty alleviation and adaptation to climate change. It enables households to generate more income, increase their resilience, and in some cases transform their livelihoods. Small-scale irrigation is a policy priority in Ethiopia for rural poverty alleviation and growth (MOFED, 2006), as well as climate adaptation. Only around 5\% of Ethiopia's irrigable land is irrigated (World Bank, 2006), and less than 5\% of total renewable water resources are withdrawn annually, so there is considerable scope for expansion.

Irrigating households reported an average $20 \%$ increase in annual income since adopting irrigation, and in some cases up to $300 \%$, due to cultivation of higher value crops, intensified production and reduced losses. Nutrition was said to have improved as various fruit and vegetables became locally available. On the other hand, production of chat is mainly located close to the road network and on farms with irrigation facilities. Similarly, most horticultural crops are produced through irrigation. So 
this scare resource, small-scale irrigated land, is allocated for fruits, vegetables or chat based on the market incentives. Economic considerations are very important in peasant farmers' resource allocation decisions. The driving forces for production of either fruits and vegetable or chat have probably been increased market opportunities and favorable prices. Thus production of chat substituting fruit and vegetables crops become farmers' alternative to ensure continued cash income. Chat has additional advantage because it can be harvested at least twice a year under rainfed agriculture while up to five harvests per year is possible under irrigation. This ensures that households have a well distributed flow of income (Tefera et. al, 2003).

Although fruits and vegetables production and export is at good growth rate with government encouragement, chat production and export is in a much more growth rate than other horticultural crops. Therefore, compromise production of these sectors is important since both of them are produced in a small piece of land with irrigation. For example, small-scale irrigation is encouraged and increased in Nile basin area of north western Ethiopia. The commodities of either chat or fruit /vegetables production is farmers alternative based on market force. In this new area chat production seems boom; there is daily supply chat for all outlets of Bahir Dar including central market Addis Ababa. According to CSA 2010, Amhara region has more than 5 thousand hectare of chat which is much of the production is around Abay basin, Lake Tana area. Chat production is expanding with an alarming rate that famers give priority for production of chat in their piece of irrigated land. This makes to slow down the very important sector fruits and vegetables production and expansion in the area. Similarly, Hararghe was known with its high available quality of fruits (citrus, mango etc.) some 20 years ago but not now, substitute with chat. In west and East Hararghe highland about 60366 ha of land is allocated for chat/chat production but only 17988ha for fruit production (CSA, 2005).

\section{Consumption and Nutritional Influence of Chat}

Ethiopia has a variety of fruits, leafy vegetables, roots and tubers adaptable to specific locations and altitudes. Horticultural crop production in Ethiopia is scattered throughout the country on patches of land in peasant smallholder farm. The major producers of horticultural crops are small scale farmers, production being mainly rain fed and few under irrigation. Shallot, garlic, potatoes and chilies are mainly produced under rain fed conditions. Tomatoes, carrots, lettuce, beetroot, cabbage, spinach and swisschard are usually restricted to areas where irrigation water is available.

The carbohydrate in vegetables and fruits has low to moderate energy value. Fruit contains protective vitamins and minerals, and dietary fiber but very little protein. They are practically fat-free except for avocado and olive, both of which contain up to $15 \%$ of fat. Vegetables generally provide between $10 \mathrm{kcal}$ and $50 \mathrm{kcal}$ per $100 \mathrm{~g}$; their nutritional advantage is that they offer a high concentration of micronutrients for low contents of calories and fat. Virtually every national or international report on diet and health recommendations calls for an increase in fruit and vegetables consumption to replace high energy foods. Despite an enormous potential and a favorable environmental and Socio-economic advantage, horticulture is relatively under developed. The margin of the current achievements, in terms of area and output is a small development compared to the possible level that can be attained (Semeret, 1992).

These eating habits create very poor consumption preferences for most of fresh fruits and vegetables. The average annual per capita consumption of horticultural crops estimated to be $48 \mathrm{~kg}$ for the rural and $37 \mathrm{~kg}$ for the urban population (Bekele, 1989). Horticultural crops play a significant role in developing country like Ethiopia, both in income and social spheres for improving income and nutrition status.

Fruit and vegetable consumption is a win-win approach as it gives added-value to the horticultural products and income to the producers. It is an efficient way to address poverty alleviation, take care of the health and well-being of the consumers, and offers new market opportunities for farmers, consumers, and agro-industry. In addition to the FAO-WHO initiative, such an approach is supported by the Global Horticultural Initiative (GlobalHort) and is now considered globally as a good way for reaching the United Nations Millenium Development Goals (MDGs). A very low consumption of Fruits and Vegetables is generally synonymous with under- nutrition and consequently under-weight (Grany, 2009).

With regards to the practice of own production/cultivation of common vegetables and fruits, the study showed a bleak picture in Ethiopia. When the fact that the proportion of households who reported to have cultivated/produced included those who had a single seedling/plant of a 
vegetable/fruit in their gardens even once over the year is considered, it is obvious that the proportion of households who produced adequate fruits and vegetables in their gardens/homesteads is negligible. Based on World Health Organization (WHO) recommendations suggesting unavailability of dark green leafy vegetables for more than six months in an area as indicative of increased risk to Vitamin A Deficiency-VAD (WHO, 1996), many regions in Ethiopia can be considered as VAD endemic.

According to Tsegaye et.al (2009) study regarding cultivation and consumption of vegetables and fruits is extremely sub-optimal in Ethiopia, calling for strengthened efforts to promote production and consumption of fruits and vegetables. The high consumption of root crops-potatoes, sweet potatoes, yams and the root of the false banana called enset (Ensete ventircosum L.), which is predominate in the south central part of the country, the eating habits in the big towns and their surroundings which is the mixture of foreign dishes and the high Landers staple food, injera and wat.

\section{SUMMARY AND CONCLUSION}

Chat is clearly an essential cash crop in Ethiopia distinguished for its foreign currency earnings. However, it is little understood and given no development and research attention yet. Millions of people both in Ethiopia and other countries are making a living from the crop. Nevertheless, it is mostly observed as a socially undesirable "drug plant".

Farmers possess considerable knowledge of the crop and appear to be the best experts of chat production than anybody else so far. They also appear to drive a substantial cash income from the sale of the chat despite the absence of technical support and massive.

It is recommended that a better understanding of the economic benefits and demerits of chat be developed through a multidisciplinary approach with the full involvement of chat growers and traders. The findings derived from such an approach should then be considered against an understanding of the negative physical and social effects of chat use/abuse before considering possible strategies to assist chat growing communities through the substitution of alternative crops, such as coffee and fruit/vegetables. Only through a balanced analysis, taking into consideration all factors (economics, social, cultural and environmental), can the cultivation, use and economics of chat are understood in a proper context.

In summary, concerning chat growing the government as well as all stockholders should involve. Reducing the addiction behaviors and mono-cropping; producing with other horticultural crops side by side to earn the income. The government interference is obligatory about the crop expansion status. It is better to have all the necessary research outputs about the crop.

\section{REFERENCE}

[1] Amare Getahun and A. D. Krikorian, 1973. Chart: Coffee's rival from Harar, Ethiopia. I. Botany, Cultivation and Use.

[2] Bekele Wolde. 1989. Horticulture marketing systems in Ethiopia. First international symposium on horticultural economics in developing countries. Acta. Horticulturae. 16 - 23 July 1989. Alemaya, Ethiopia. PP. 21 - 31.

[3] Central Statistical Agency (CSA) of Ethiopia website: http://www.csa.gov.et/, last accessed, October 30, 2016. Addis Ababa, Ethiopia.

[4] Dechassa Lemessa. Chat (Catha edulis): Botany, Distribution,Cultivation, Usage and Economics in Ethiopia. UN Emergencies Unit for Ethiopia, Addis Ababa, 2001.

[5] Feyisa, T. H. and Aune, J. B. (2003) Chat Expansion in the Ethiopian Highlands: Effects on the Farming System in Habro District in Mountain Research and Development, Vol. 23, pp.186-190.

[6] Grany J., 2009. Current Status of Fruits and Vegetables Production and Consumption in Francophone African Countries - Potential Impact on Health. CIRAD, France.

[7] Guinand Y. 1999. Mission Report-East and West Hararghe, UN-Emergencies Unit for Ethiopia.

[8] Haileab A., Haileselassie T. and Wondoson T., 2011. Current status and development prospects of export oriented fruits, vegetables and herbs production in Ethiopia. Third Biennial Conference of the Ethiopian Horticultural Science Society (EHSS). Horticulture development agency, Addis Ababa, Ethiopia 
Tesfa Binalfew "The Expansion of Production, Marketing and Consumption of Chat in Ethiopia"

[9] Klein A., 2008. Chat and the Informal Globalization of a Psychoactive Commodity; Illicit Trade and Globalization. CESifo Venice Summer Institute: 14-15 July 2008

[10] Klingele, R. (1998). Hararghe Farmers on the Crossroad between Subsistence and Cash Economy. Unpublished report. UNDP: Addis Ababa.

[11] Lamina S. 2010. Chat (Catha edulis): The herb with officio-legal, socio-cultural and economic uncertainty. S Afr J Sci. 2010; 106 (3/4), Art. \#155, 4 pages. DOI: 10.4102/sajs. v106i3/4.155

[12] Lautze S., Aklilu Yacob, Raven-Roberts. A, Young H., Kebede Girma, Leaning J., 2003. Risk and vulnerability in Ethiopia: learning from the past, responding to the present, preparing for the future. A Report for the U.S. Agency for International Development

[13] MOFED (Ministry of Finance and Economic Development) (2006) Ethiopia: Building on Progress. A Plan for Accelerated and Sustained Development to End Pove rt y $2005 / 6$ 2009/10. September 2006.

[14] Raman R. Catha edulis Forsk, Geographical Dispersal, Botanical, Ecological and Agronomical Aspects with Special References to Yemen Arab Republic. PhD Thesis, University of Gottingen: Germany, 1983.

[15] Selassie S G, Gebre A (1996). Rapid Assessment of Drug Abuse in Ethiopia. UNODC - Bull. Narc., 191996. 1(4):53-63.

[16] Semeret K-Yesus. 1992. Horticultural development in peasant agriculture. Second Eth. Hort. workshop (Edward Herath and Lemma Dessalegne eds.). Horticulture research and development in Ethiopia. 1 - 3 December 1992. Addis Ababa, Ethiopia. PP. 29-

[17] Seyoum. E, Kidane.Y, Gebru.H, and Sevenhuysen. G., 2001. Preliminary study of income and nutritional status indicators in two Ethiopian communities. Ethiopian Nutrition Institute, Addis Ababa, Ethiopia and Department of Foods and Nutrition, University of Manitoba, Winnipeg, Canada

[18] Tefera TL, Kirsten JK, Perret S. Market Incentives, Farmers' Response and A Policy Dilemma: A case study of chat production in the eastern Ethiopian highlands. Agrekon 2003:42(3): 213-27.

[19] Tesfaye Lemma, J. Kirsten and S. Perret, 2003. Market Incentives, Farmers' Response and A Policy Dilemma: A Case Study on Expansion of Chat Production as a Cash Crop in the Eastern Ethiopian Highlands. Alemaya Univesity, Ethiopia and University of Pretoria, South Africa

[20] The Reporter. 2000. Vol.V No. 219, dated 15 November Addis Ababa, Ethiopia.

[21] Tsegaye Demissie, Ahmed Ali, Dilnesaw Zerfu (2009), Availability and consumption of fruits and vegetables in nine regions of Ethiopia with special emphasis to vitamin A deficiency. Ethiopia Journal of Health Development, 2009; 23 (3):216-222.

[22] World Health Organization (WHO), 1996. Indicators for assessing Vitamin A deficiency and their application in monitoring and evaluating intervention programs. WHO, Geneva 